\title{
Aderência de Actinobacillus actinomycetemcomitans às células epiteliais bucais: estabilidade e aspectos ultra-estruturais
}

\section{Actinobacillus actinomycetemcomitans attached to oral epithelial cells: stability and ultrastructural aspects}

\author{
André GASPARETTO* \\ Victor Elias ARANA-CHAVEZ** \\ Mario Julio AVILA-CAMPOS***
}

\begin{abstract}
GASPARETTO, A.; ARANA-CHAVEZ, V. E.; AVILA-CAMPOS, M. J. Aderência de Actinobacillus actinomycetemcomitans às células epiteliais bucais: estabilidade e aspectos ultra-estruturais. Pesqui Odontol Bras, v. 14, n. 4, p. 311-318, out./dez. 2000.
\end{abstract}

\begin{abstract}
Actinobacillus actinomycetemcomitans é considerado um importante patógeno na doença periodontal, particularmente na periodontite juvenil localizada. O mecanismo de adesão bacteriana às células epiteliais bucais (CEB), aos dentes e a outras bactérias, constitui-se o passo inicial na colonização e patogênese nos quadros de gengivite e periodontite. Neste estudo, avaliou-se a aderência às CEB, a sua variabilidade e os aspectos ultra-estruturais de 21 isolados e de uma cepa de referência de A. actinomycetemcomitans, quando submetidos a repiques sucessivos. Todos os isolados testados aderiram às CEB e os repiques sucessivos determinaram variações nas taxas de aderência de cada isolado. Os isolados que apresentaram altos índices de aderência também produziram quantidades elevadas de componentes extracelulares, tais como fimbrias, vesículas e/ou material amorfo extracelular.
\end{abstract}

UNITERMOS: Aderência bacteriana; Actinobacillus actinomycetemcomitans; Doenças periodontais.

\section{INTRODUÇÃO}

A doença periodontal constitui a principal causa da perda dos dentes na população adulta, representando um dos mais sérios problemas sócio-econômicos e de saúde pública em âmbito mundial. Considerando-se este impacto social e econômico, torna-se urgente a solução do problema, envolvendo aspectos clínicos e laboratoriais, procurando-se recursos mais eficientes para o diagnóstico, tratamento e prevenção destas doenças.

Bactérias gram-negativas anaeróbias bucais são os principais organismos associados com a causa e desenvolvimento das gengivites e periodontites ${ }^{15}$, pretendendo-se hoje associar agentes específicos a diferentes quadros infecciosos do periodonto. Com o aparecimento da hipótese da placa específica, passou-se a atribuir a determinados microrganismos um papel especial nas distintas entidades clínicas de cárie e doença periodontal ${ }^{9,15}$.

Actinobacillus actinomycetemcomitans, consti- tuinte da microbiota bucal indígena, é considerado um importante patógeno na doença periodontal, em adultos e em pacientes jovens ${ }^{18}$. Entretanto, o conhecimento a respeito da colonização e persistência dessa bactéria na cavidade bucal é limitado $^{6}$. Para que ocorra colonização da cavidade bucal, é primordial a aderência bacteriana aos dentes e/ou às superficies mucosas. Assim, microrganismos que não possuam mecanismos de adesão serão facilmente removidos pelos fluidos bucais ${ }^{7}$.

A adesão de $A$. actinomycetemcomitans às superfícies de células epiteliais, aos dentes e/ou a outras bactérias bucais, assim como a invasão à gengiva, constituem passos iniciais e essenciais na patogênese dos processos periodontais ${ }^{13}$. Estudos mostram que a capacidade de aderência deste microrganismo às células epiteliais bucais ou à hidroxiapatita estaria associada às fimbrias, vesículas extracelulares e/ou material amorfo extracelular ${ }^{8,13}$. Considerando-se a importância do A. actinomycetemcomitans na patogênese das doenças

* Mestre em Microbiologia; ** Professor Doutor do Departamento de Histologia e Embriologia; *** Professor Doutor do Departamento de Microbiologia - Instituto de Ciências Biológicas da USP. 
GASPARETTO, A.; ARANA-CHAVEZ, V. E.; AVILA-CAMPOS, M. J. Aderência de Actinobacillus actinomycetemcomitans às células epiteliais bucais: estabilidade e aspectos ultra-estruturais. Pesqui Odontol Bras, v. 14, n. 4, p. 311-318, out./dez. 2000.

periodontais, por meio de seus diversos fatores de virulência, particularmente aqueles envolvidos no processo de aderência ao epitélio bucal humano, torna-se necessário aprofundar as observações sobre a estabilidade deste mecanismo, visando a um melhor conhecimento da agressão deste grupo microbiano. Neste trabalho, foi avaliada a aderência às células do epitélio bucal humano de isolados de Actinobacillus actinomycetemcomitans, a sua variabilidade e a sua subseqüente estabilidade estrutural.

\section{MATERIAL E MÉTODOS Espécimes coletados e isolamento bacteriano}

Os espécimes foram coletados conforme metodologia preconizada por SLOTS ${ }^{17}$ e AVILA-CAMPOS et al. ${ }^{1}$ e obtidos de 21 pacientes com quadros severos de periodontite juvenil e do adulto, com bolsas periodontais com $5 \mathrm{~mm}$ ou mais de profundidade, de 17 a 41 anos de idade, atendidos na Clínica de Periodontia da Faculdade de Odontologia da Universidade de São Paulo e que não utilizaram antimicrobianos nos seis meses que antecederam a coleta.

Os espécimes foram coletados com auxílio de cones de papel absorvente esterilizados, introduzidos nas bolsas onde permaneciam por 30 segundos, sendo transportados em solução RingerPRAS, pH 7,2, sob fluxo de $\mathrm{CO}_{2}$ num intervalo de 2 horas. Alíquotas de 0,1 ml de diluições seriadas na mesma solução e sob fluxo de $\mathrm{CO}_{2}$, foram plaqueadas em ágar de soja tripticaseína-soro de cavalo-bacitracina-vancomicina (TSBV $)^{17}$. As placas, em duplicata, foram incubadas em dessecadores de vidro criando-se condições de anaerobiose $190 \%$ $\mathrm{N}_{2} / 10 \% \mathrm{CO}_{2}$ ), a $37^{\circ} \mathrm{C}$, por 72 horas. Posteriormente, as colônias sugestivas de A. actinomycetemcomitans foram repicadas em ágar-sangue, para obtenção de cultura pura e incubadas em condições de microaerofilia (método da vela), a $37^{\circ} \mathrm{C}$, por 48 horas. Os isolados foram confirmados como $A$. actinomycetemcomitans por meio da produção de catalase, coloração de Gram, sensibilidade ao fluoreto de sódio $(100 \mu \mathrm{g} / \mathrm{ml})$ e pela fermentação de carboidratos $^{18}$. A cepa de referência $A$. actinomycetemcomitans FDC Y4 foi utilizada como controle em todos os testes.

\section{Aderência às células epiteliais bucais (CEB)}

Os testes de aderência às CEB foram realizados segundo CHILDS III; GIBBONS ${ }^{4}$. Os isolados de $A$. actinomycetemcomitans foram cultivados em caldo de soja tripticaseína suplementado com $0,5 \%$ de extrato de levedura (TSB-YE) (Difco Laboratories, MA, EUA), adicionado de metil-timidina tritiada na concentração final de $5 \mu \mathrm{l} / \mathrm{ml}$ (Amersham Life Science, EUA), em condições de microaerofilia, a $37^{\circ} \mathrm{C}$, por 48 horas. Posteriormente, as células bacterianas foram precipitadas por centrifugação, a $3.000 \mathrm{~g}$, a $4^{\circ} \mathrm{C}$, por $3 \mathrm{~min}$, e o sobrenadante foi eliminado. O sedimento foi ressuspendido em solução salina tamponada fosfatada (STF, pH 7,2), ajustando-se a concentração celular bacteriana para aproximadamente $5 \times 10^{7}$ células $/ \mathrm{ml}$ em espectrofotômetro (Beckman Instruments, EUA) $\mathrm{A}_{480 \mathrm{~nm}}=0,18$. As CEB foram obtidas a partir de um único doador (masculino, sadio, grupo sanguíneo O, Rh-positivo) por meio da raspagem do epitélio bucal com auxílio de espátula esterilizada de madeira. A massa epitelial obtida, foi ressuspendida em STF e lavadas ( $\left.1.000 \mathrm{~g}, 4^{\circ} \mathrm{C}, 5 \mathrm{~min}\right)$, ajustando-se a suspensão para $2 \times 10^{5} \mathrm{CEB} / \mathrm{ml}$, com câmara de neubauer.

\section{Avaliação da aderência bacteriana às CEB}

Foram depositados em tubo Eppendorf $75 \mu 1$ da suspensão bacteriana e $75 \mu \mathrm{l}$ da suspensão de $\mathrm{CEB}$, padronizados, e mantidos em rotação $(6 \mathrm{rpm}$, 2 horas), à temperatura ambiente, em aparelho Roto-Torque Mod. 7.637 (Cole-Parmer Ind. Co., EUA). Posteriormente, a mistura $(150 \mu 1)$ foi transferida para tubo Ultraclear (Beckman Instruments, EUA) contendo $4 \mathrm{ml}$ de Percoll (50\%) (Sigma-Aldrich Chemical Co., MO, EUA), centrifugando-se a $31.000 \mathrm{~g}, 4^{\circ} \mathrm{C}, 20 \mathrm{~min}$ (rotor SW-50.1, Beckman Instruments, EUA).

Após a centrifugação, a fase superior $(1 \mathrm{ml})$ foi removida, diluída em $100 \mathrm{ml}$ de STF, e filtrada em membranas de éster de celulose $(47 \mathrm{~mm}$ de diâmetro e $0,8 \mu \mathrm{m}$ de porosidade, Millipore). Como controle, filtraram-se $75 \mu 1$ da suspensão bacteriana. As membranas foram secas e transferidas para tubos Eppendorf acrescidos de 1,2 ml de líquido de cintilação e introduzidos em frascos apropriados para leitura em aparelho de cintilação LS 5000 TD (Beckman Instruments, EUA). Todos os testes foram realizados em triplicata.

\section{Variabilidade da aderência bacteriana às CEB}

O estudo do comportamento microbiano no processo de aderência foi realizado por meio de repiques sucessivos dos isolados em meio TSB-YE, com intervalos programados de 10 em 10 repiques, de 24 a 48 horas de crescimento, atingindo-se o to- 
GASPARETTO, A.; ARANA-CHAVEZ, V. E.; AVILA-CAMPOS, M. J. Aderência de Actinobacillus actinomycetemcomitans às células epiteliais bucais: estabilidade e aspectos ultra-estruturais. Pesqui Odontol Bras, v. 14, n. 4, p. 311-318, out./dez. 2000.

tal de 30 subcultivos. O processo de adesão às CEB foi realizado ao final de cada 10 subcultivos.

\section{Estudo ultra-estrutural}

Foi realizado examinando-se as características das bactérias recém-isoladas e daquelas aderidas às $\mathrm{CEB}$ e, posteriormente, após cada 10 subcultivos.

\section{Microscopia eletrônica de transmissão (MET)}

As amostras foram fixadas em solução de glutaraldeído (2\%), formaldeído $(2,5 \%)$ e tampão cacodilato de sódio $(0,1 \mathrm{M}, \mathrm{pH} 7,4)$, durante 4 horas. Em seguida, foram lavadas com o mesmo tampão e pós-fixadas em tetróxido de ósmio (1\%), por 2 horas. As amostras foram desidratadas com álcool e com acetona e, finalmente, incluídas em resina Spurr (Electron Microscopy Sciences, EUA). Os blocos obtidos foram cortados em ultramicrótomo Sorvall MT2-B com facas de vidro e corados com azul de toluidina $(0,25 \%)$ para observação em microscópio óptico de luz. Estes cortes, coletados em telas de cobre de 200 ou 300 meshes (Electron Microscopy Sciences, EUA), foram contrastados com solução alcoólica de acetato de uranila (2\%) e citrato de chumbo $(0,5 \%)$. As bactérias cultivadas em meio liquido foram depositadas em tubo Eppendorf e contrastados pela adição de ácido fosfotúngstico a $2 \%$. Após 30 segundos, alíquotas desta mistura foram depositadas sobre telas de cobre. Finalmente, todas as preparações foram examinadas e fotografadas em MET JEOL 100 CX II.

\section{Microscopia eletrônica de varredura (MEV)}

As amostras foram fixadas, pós-fixadas e desidratadas, como descrito para a MET. Em seguida, foram dessecadas pelo método do ponto crítico em aparelho Balzers CPD-030 (Electron Microscopy Sciences, EUA) em suportes de alumínio e cobertos com ouro em aparelho metalizador Balzers SCD-050 (Electron Microscopy Sciences, EUA). Posteriormente, o material foi examinado e fotografado em MEV JEOL 6.100.

\section{Análise estatística}

Os dados obtidos foram submetidos a análise de variância com medidas repetidas, para determinação da significância da diferença nos ensaios com cada bactéria. Posteriormente, aplicaram-se duas comparações múltiplas para verificar, em cada isolado, a existência de diferença significante da porcentagem de bactérias aderidas às CEB entre os ensaios. A suposição de homocedasticidade dos grupos foi satisfeita, na maioria dos casos, com transformação nos dados, sendo adotado o nível de significância $p<0,05$.

\section{RESULTADOS}

De cada espécime periodontal positivo, foi obtido um isolado de $A$. actinomycetemcomitans (Tabela 1). Em isolamento primário, todas as colônias apresentavam-se convexas, ligeiramente irregulares e com aspecto interno em forma de estrela, com diâmetro de $1 \mathrm{~mm}$, característico da espécie. Essas colônias, quando repicadas em ágar-sangue, mantiveram a dimensão colonial, tornando-se lisas e sem a estrutura interna típica. A identificação foi

TABELA 1 - Características clínicas, sexo e idade dos pacientes portadores de doença periodontal.

\begin{tabular}{|c|c|c|c|c|}
\hline $\begin{array}{c}\text { Isolado } \\
\left(\mathrm{N}^{\mathrm{o}}\right)\end{array}$ & $\operatorname{Sexo}^{a}$ & Idade $^{\mathrm{b}}$ & $\begin{array}{c}\text { Elemento } \\
\text { dental }^{c}\end{array}$ & $\begin{array}{c}\text { Profundidade } \\
\text { das bolsas } \\
\text { periodontais }\end{array}$ \\
\hline 1 & $\mathrm{M}$ & 33 & 17 & 10 \\
\hline 3 & $\mathrm{M}$ & 39 & 25 & 8 \\
\hline 4 & $\mathrm{~F}$ & 28 & 47 & 7 \\
\hline 8 & $\mathrm{M}$ & 21 & 15 & 7 \\
\hline 10 & $\mathrm{M}$ & 38 & 27 & 9 \\
\hline 11 & $\mathrm{M}$ & 40 & 17 & 10 \\
\hline 12 & $\mathrm{M}$ & 19 & 45 & 11 \\
\hline 14 & $\mathrm{~F}$ & 29 & 22 & 8 \\
\hline 15 & $\mathrm{M}$ & 17 & 21 & 7 \\
\hline 18 & $\mathrm{M}$ & 29 & 16 & 7 \\
\hline 24 & $\mathrm{~F}$ & 19 & 14 & 10 \\
\hline 26 & $\mathrm{~F}$ & 19 & 34 & 8 \\
\hline 28 & $\mathrm{~F}$ & 35 & 42 & 8 \\
\hline 30 & $\mathrm{M}$ & 32 & 34 & 10 \\
\hline 35 & $\mathrm{~F}$ & 33 & 26 & 11 \\
\hline 36 & $\mathrm{~F}$ & 30 & 27 & 5 \\
\hline 37 & $\mathrm{M}$ & 18 & 42 & 14 \\
\hline 38 & $\mathrm{~F}$ & 26 & 11 & 10 \\
\hline 39 & $\mathrm{M}$ & 26 & 31 & 7 \\
\hline 41 & $\mathrm{M}$ & 32 & 35 & 11 \\
\hline 45 & $\mathrm{~F}$ & 22 & 21 & 6 \\
\hline
\end{tabular}

a M: masculino; F: feminino. b Idade em anos. c Número do elemento dental coletado. d Valores expressos em milimetros. 
GASPARETTO, A.; ARANA-CHAVEZ, V. E.; AVILA-CAMPOS, M. J. Aderência de Actinobacillus actinomycetemcomitans às células epiteliais bucais: estabilidade e aspectos ultra-estruturais. Pesqui Odontol Bras, v. 14, n. 4, p. 311-318, out./dez. 2000.

confirmada pela produção de catalase, sensibilidade à solução de fluoreto de sódio e pela fermentação de carboidratos.

Os isolados de A. actinomycetemcomitans, quando cultivados em meio líquido, mostraram um crescimento granular e aderidas às paredes do tubo, sem turvar o meio. Após aproximadamente cinco repiques e variando para cada isolado, essa característica auto-agregativa era perdida, passando a turvar uniformemente o meio. O crescimento inicial em caldo de soja tripticaseína mostrou que 17 dos isolados estudados apresenta- vam-se fortemente agregados, formando grumos e sem turvar o meio de cultivo. Também, os isolados $15,28,30$ e 39 e a cepa FDC Y4 turvaram o meio; pela coloração de Gram, foi observada intensa coloração entre as células fortemente agregadas, sugerindo-se a presença de abundante quantidade de estruturas extracelulares. Entretanto, na cepa Y4 não foi observada a mesma aparência, o que pode ser explicado pelos repiques laboratoriais realizados para sua manutenção. Também foi observado que, a partir do décimo subcultivo, alguns isolados de A. actinomycetemcomitans apresenta-

TABELA 2 - Comportamento de 22 cepas de A. actinomycetemcomitans no processo de aderência às CEB, em vários subcultivos.

\begin{tabular}{|c|c|c|c|c|c|}
\hline \multirow{2}{*}{$\frac{\text { Cepa }}{\mathrm{N}^{\circ}}$} & \multicolumn{5}{|c|}{ Valor de aderência em cada subcultivo* $\mathrm{X} \pm \mathrm{DP} * *$} \\
\hline & $1^{\circ}$ & $10^{\circ}$ & $20^{\circ}$ & $30^{\circ}$ & $\mathrm{P}$ \\
\hline 1 & $63,05 \pm 54,12$ & $101,55 \pm 22,5$ & $58,95 \pm 17,2$ & $42,22 \pm 18,17$ & 0,206 \\
\hline 3 & $17,92 \pm 2,77$ & $6,0 \pm 1,10$ & $65,27 \pm 4,22$ & $8,95 \pm 0,22$ & 0,000 \\
\hline 4 & $3,15 \pm 0,9$ & $34,5 \pm 8,6$ & $29,22 \pm 6,02$ & $58,95 \pm 17,62$ & 0,001 \\
\hline 8 & $15,82 \pm 8,12$ & $36,82 \pm 2,37$ & $34,07 \pm 4,5$ & $51,67 \pm 21,95$ & 0,049 \\
\hline 10 & $10,42 \pm 11,3$ & $89,42 \pm 9,42$ & $66,5 \pm 6,2$ & $21,95 \pm 8,95$ & 0,000 \\
\hline 11 & $4,37 \pm 0,87$ & $14,3 \pm 2,62$ & $14,85 \pm 2,32$ & $18,3 \pm 1,85$ & 0,001 \\
\hline 12 & $23,77 \pm 9,92$ & $54,32 \pm 18,35$ & $8,72 \pm 2,47$ & $70,52 \pm 28,97$ & 0,000 \\
\hline 14 & $61,97 \pm 78,05$ & $83,47 \pm 22,17$ & $46,95 \pm 8,7$ & $58,25 \pm 5,47$ & 0,001 \\
\hline 15 & $159,35 \pm 48,67$ & $44,62 \pm 2,55$ & $15,1 \pm 2,57$ & $7,22 \pm 2,0$ & 0,000 \\
\hline 18 & $66,12 \pm 6,35$ & $113,92 \pm 17,42$ & $37,45 \pm 20,62$ & $40,42 \pm 9,55$ & 0,002 \\
\hline 24 & $73,6 \pm 80,95$ & $8,6 \pm 2,6$ & $18,9 \pm 1,27$ & $14,4 \pm 1,85$ & 0,010 \\
\hline 26 & $8,65 \pm 2,95$ & $61,92 \pm 10,17$ & $76,62 \pm 6,95$ & $74,35 \pm 6,25$ & 0,000 \\
\hline 28 & $134,37 \pm 50,8$ & $35,9 \pm 2,92$ & $25,05 \pm 4,87$ & $7,72 \pm 2,7$ & 0,000 \\
\hline 30 & $165,47 \pm 44,05$ & $29,12 \pm 6,45$ & $18,72 \pm 3,37$ & $12,85 \pm 0,95$ & 0,000 \\
\hline 35 & $25,4 \pm 2,05$ & $106,75 \pm 39,12$ & $43,47 \pm 3,4$ & $69,42 \pm 3,12$ & 0,000 \\
\hline 36 & $22,07 \pm 0,87$ & $108,37 \pm 6,75$ & $66,75 \pm 4,8$ & $54,7 \pm 7,82$ & 0,000 \\
\hline 37 & $23,7 \pm 4,57$ & $119,07 \pm 1,32$ & $88,87 \pm 6,65$ & $55,72 \pm 3,2$ & 0,000 \\
\hline 38 & $81,45 \pm 55,72$ & $30,67 \pm 7,07$ & $27,22 \pm 23,37$ & $25,02 \pm 5,1$ & 0,155 \\
\hline 39 & $148,8 \pm 89,7$ & $11,27 \pm 0,65$ & $5,85 \pm 2,02$ & $23,07 \pm 2,2$ & 0,000 \\
\hline 41 & $76,2 \pm 19,97$ & $6,95 \pm 43,77$ & $113,37 \pm 12,7$ & $13,52 \pm 1,12$ & 0,000 \\
\hline 45 & $65,27 \pm 55,7$ & $43,12 \pm 3,22$ & $40,17 \pm 5,67$ & $10,55 \pm 2,0$ & 0,002 \\
\hline Y4 & $52,97 \pm 62,92$ & $44,42 \pm 6,82$ & $35,02 \pm 4,3$ & $60,6 \pm 24,35$ & 0,834 \\
\hline
\end{tabular}

* Valores expressos em número de celulas bacterianas aderidas às CEB, em relação ao controle. Testes realizados em triplicata. ** Média \pm desvio-padrão. 
GASPARETTO, A.; ARANA-CHAVEZ, V. E.; AVILA-CAMPOS, M. J. Aderência de Actinobacillus actinomycetemcomitans às células epiteliais bucais: estabilidade e aspectos ultra-estruturais. Pesqui Odontol Bras, v. 14, n. 4, p. 311-318, out./dez. 2000.

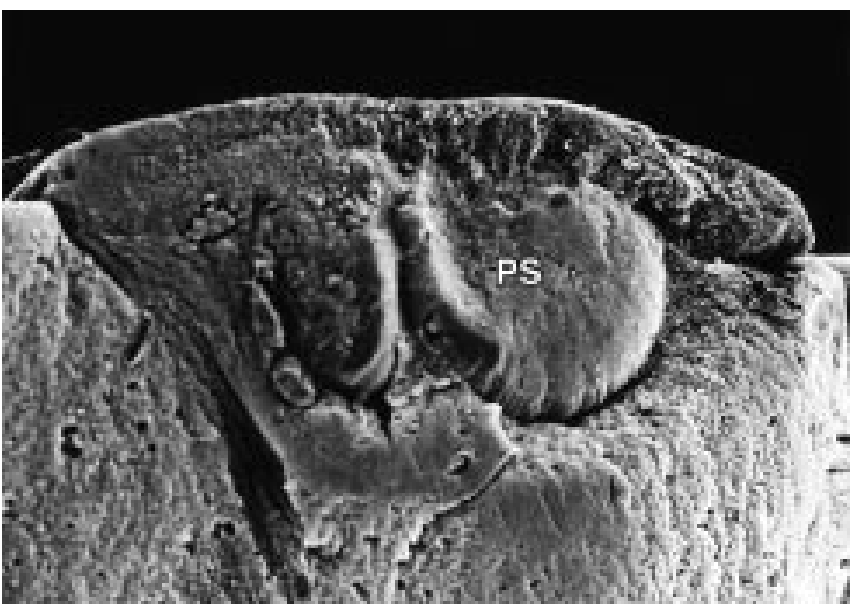

FIGURA 1 - Micrografia eletrônica de varredura, observando-se em corte sagital a colônia de A. actinomycetemcomitans recém-isolada e os pseudópodos (PS) no interior do ágar (270 X).

ram pleomorfismo celular acentuado, confirmado através da MET.

O teste de aderência revelou que todos os isolados testados apresentaram significativa aderência às CEB (> 50\%) do total de células inoculadas, observando-se diferenças quantitativas entre os isolados, bem como nos diferentes subcultivos (Tabela 2). No décimo subcultivo, 14 dos 21 isolados testados apresentaram significativo aumento nas taxas de aderência, provavelmente devido à perda da capacidade de formar grumos. A análise estatística não detectou diferença significante entre os isolados $1(p=0,206), 38(p=0,155)$ e Y4 $(p=0,834)$.

Na Figura 1, observa-se a colônia recém-isolada de A. actinomycetemcomitans em corte sagital, através da MEV, visualizando-se estruturas semelhantes a pseudópodos introduzidos no meio de cultura. Na Figura 2, observa-se a formação e liberação de vesículas extracelulares e a presença de material amorfo extracelular. Na Figura 2A, visualiza-se o alargamento do espaço periplásmico, bem como a liberação de algumas microvesículas. Nas Figuras 2B e 2C, observa-se o crescimento do espaço periplásmico, resultando na formação de macrovesículas e microvesículas associadas externamente à sua membrana.

\section{DISCUSSÃO}

A compreensão sobre o processo de aderência e sobre alterações morfofisiológicas após subcultivos de $A$. actinomycetemcomitans às CEB é prejudicada devido ao pequeno número de trabalhos observados na literatura ${ }^{6}$. No nivel morfocolonial, a observação dos pseudópodos em A. actinomycetemcomitans sugere que estas estruturas são, provavelmente, as responsáveis pela determinação do aspecto estrelado da colônia, concordando com BLIX et al. ${ }^{2}$ Este aspecto morfocolonial está provavelmente relacionado ao tipo de interação intercelular e ao plano em que a divisão celular ocorre. Nesse sentido, a formação de grumos, quando a bactéria é cultivada em meio líquido, sugere alguma relação entre a proliferação celular e a forma da colônia recém-isolada, estrelada ou em grumos. O acúmulo de produtos extracelulares sugere a formação de septo e sua conseqüente divisão, característica não relatada na literatura sobre o A. actinomycetemcomitans.

A metodologia empregada na marcação do microrganismo, com compostos radioativos, revelou-se adequada. O emprego de células epiteliais de um único doador foi escolhido como forma de diminuir os fatores que estariam associados com o uso de células de doadores diversos, conforme empregado por CHILDS; GIBBONS ${ }^{4}$. Esta justificativa é fortalecida pelo fato de o presente trabalho verificar o comportamento longitudinal, o que dificultaria a reposição de estoques celulares dos mesmos doadores e elimina a necessidade de estocar as $\mathrm{CEB}$, evitando-se possíveis alterações decorrentes do armazenamento.

As concentrações celulares empregadas permitiram variações nos indices de aderência, característica que evidencia a não-saturação de possiveis sítios de ligação entre as superficies celulares (Figura 3). Tal aspecto tem importância devido ao fato de A. actinomycetemcomitans, mesmo quando subcultivado, poder permanecer agrupadas em duas ou mais células, conforme relatado por MEYER; FIVES-TAYLOR ${ }^{12}$.

O uso de gradientes de densidade para separação das células bacterianas não aderidas pela força gravitacional, mostrou-se oportuno quanto à remoção destas células. Entretanto, quando as células bacterianas apresentavam-se em grumos, observou-se dificuldade em transferir as alíquotas de células bacterianas, por causa do aspecto granuloso. Esta característica parece ser responsável pela quantidade de bactérias aderidas às CEB, visto que a massa microbiana tende a precipitar no gradiente de densidade empregado, a 35.000 vezes a gravidade. Assim sendo, a força gravitacional imprimida à amostra pode ter sido maior que a força resultante da aderência das células de A. acti- 
GASPARETTO, A.; ARANA-CHAVEZ, V. E.; AVILA-CAMPOS, M. J. Aderência de Actinobacillus actinomycetemcomitans às células epiteliais bucais: estabilidade e aspectos ultra-estruturais. Pesqui Odontol Bras, v. 14, n. 4, p. 311-318, out./dez. 2000.

FIGURA 2 - Micrografia eletrônica de transmissão, contrastada com acetato de uranila e citrato de chumbo, observando-se na superficie de $A$. actinomycetemcomitans a formação e liberação de vesículas (V) e a presença de material amorfo extracelular.

Observe os diferentes estágios de formação vesicular (100.000 X): A) alargamento do espaço periplásmico e liberação de algumas microvesículas; B e C) crescimento do espaço periplásmico, resultando na formação de macrovisículas e microvesículas associadas externamente à sua membrana.

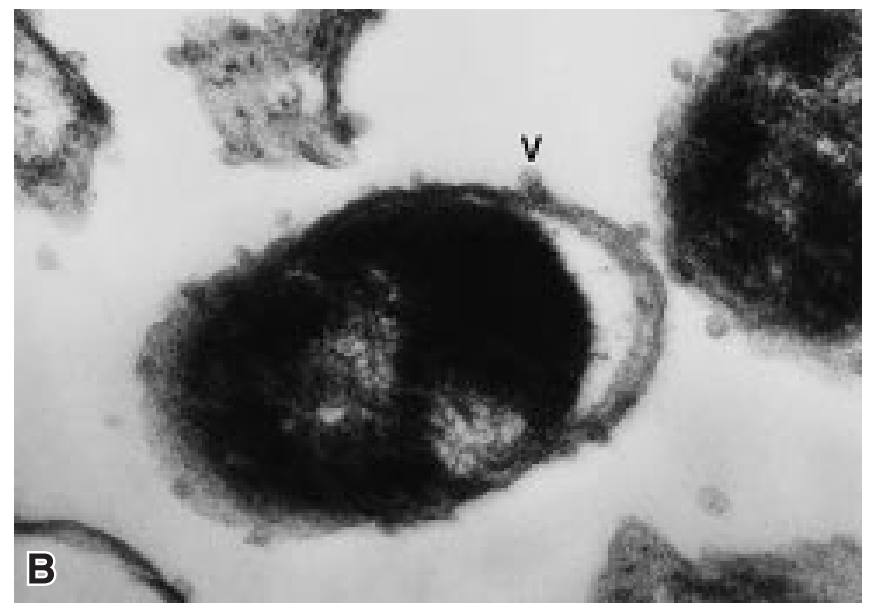

nomycetemcomitans à superficie da CEB. O processo de centrifugação poderia ter precipitado esses grumos, resultando significativo desvio-padrão, o qual foi observado nos testes em subcultivos iniciais.

Por outro lado, as condições de crescimento microbiano in vivo são diferentes das laboratoriais, assim como os nutrientes e atmosfera, entre outros, podendo produzir alterações fisiológicas do microrganismo ${ }^{3}$. A heterogeneidade deste grupo microbiano, junto com as diferenças genotípicas, pode estar também relacionada às modificações decorrentes da desagregação colonial, implicando em redução do tempo de crescimento e podendo trazer conseqüências sobre a sintese de constituintes bacterianos, em especial sobre suas adesinas ${ }^{10}$.

Na Tabela 2, observam-se os valores dos ensaios de adesão de $A$. actinomycetemcomitans às CEB. KAGERMEIER; LONDON ${ }^{8}$ demonstraram que $A$. actinomycetemcomitans é variável na sua capacidade de aderir às superfícies bucais. Alterações na
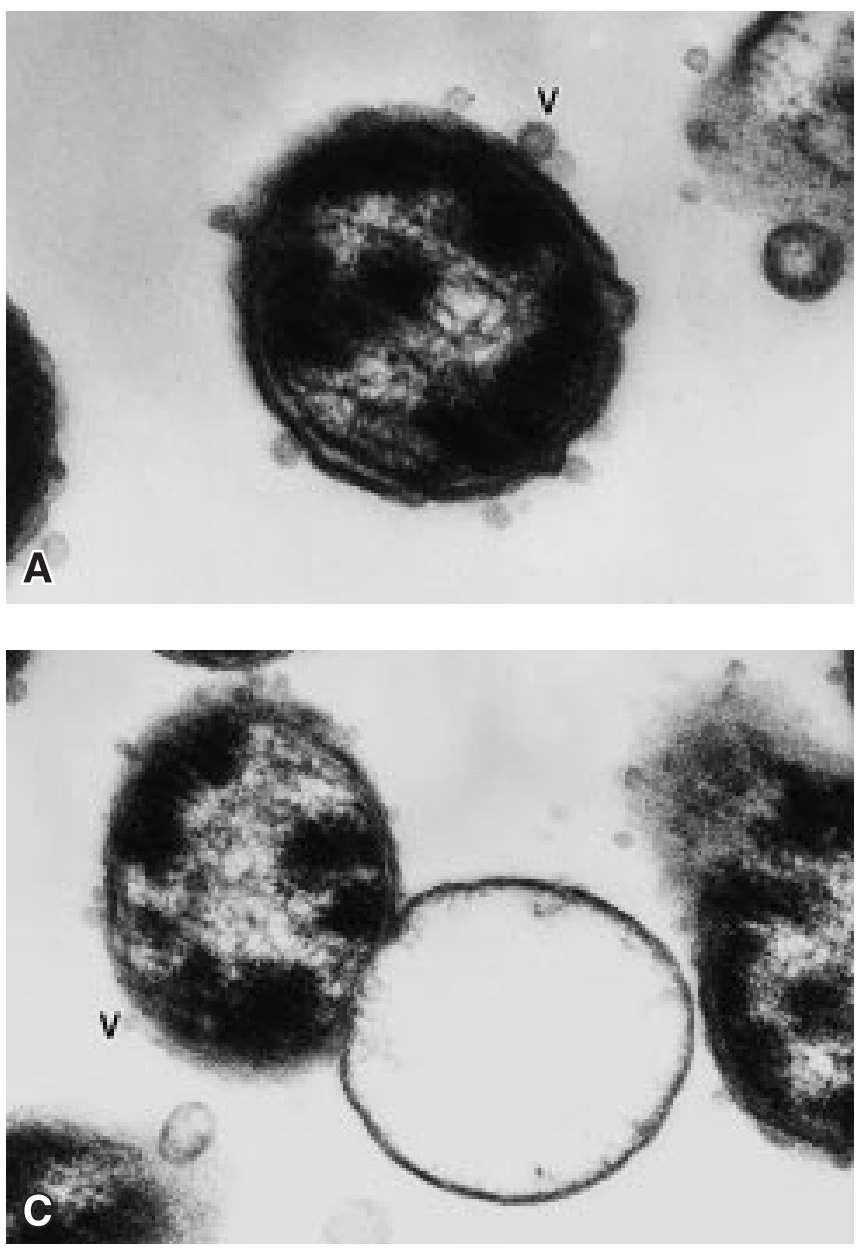

adesão também foram observadas por MEYER et al. ${ }^{11}$, testando cepas de A. actinomycetemcomitans lisas e rugosas, em que as lisas apresentaram maior capacidade invasiva que as rugosas.

A cepa de referência Y4 apresentou variações nos resultados, porém estatisticamente não significantes. Isso também pode estar relacionado ao estado fisiológico do microrganismo, derivado do subcultivo in vitro. MEYER et al. ${ }^{11}$, avaliando a capacidade invasiva de $A$. actinomycetemcomitans, observaram que cepas Y4 de diferentes fontes apresentaram resultados distintos, porém sem a comprovação estatística. Os resultados obtidos neste estudo evidenciam a forte capacidade de aderência de $A$. actinomycetemcomitans às CEB, processo mediado por estruturas extracelulares. Também, observou-se que a capacidade de aderência foi constante, embora quantitativamente variável, no decorrer dos subcultivos.

A formação de estruturas vesiculares, associada ao fato de não ser observada eletrodensidade, sugere que a mesma não deve ser de natureza apenas 
GASPARETTO, A.; ARANA-CHAVEZ, V. E.; AVILA-CAMPOS, M. J. Aderência de Actinobacillus actinomycetemcomitans às células epiteliais bucais: estabilidade e aspectos ultra-estruturais. Pesqui Odontol Bras, v. 14, n. 4, p. 311-318, out./dez. 2000.

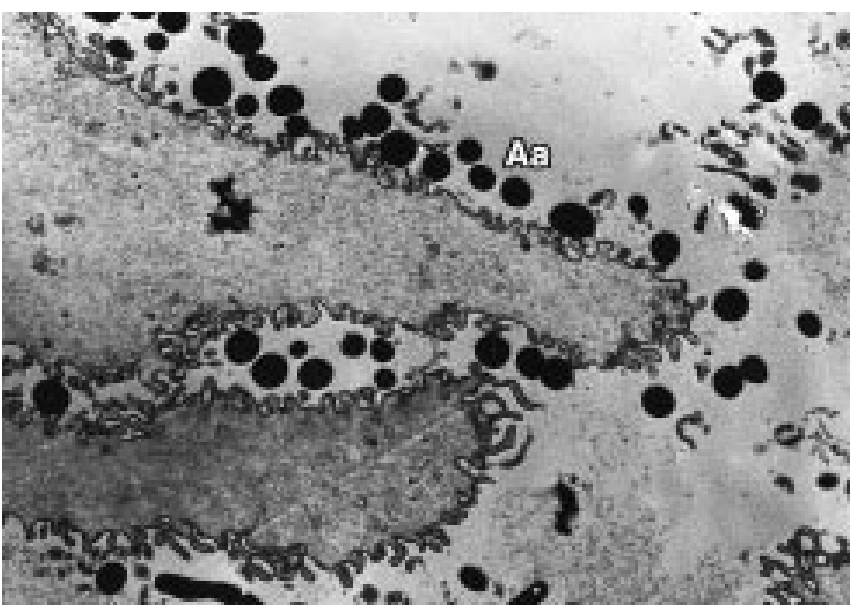

FIGURA 3 - Micrografia eletrônica de transmissão, contrastada com acetato de uranila e citrato de chumbo, observando-se células de $A$. actinomycetemcomitans (Aa) aderidas à superficie da CEB (11.800 X).

secretora. Este achado concorda com o mecanismo de formação vesicular a partir da membrana externa, proposto por WENSINK; WITHOLT ${ }^{19}$ que sugerem que seria conseqüência do crescimento mais rápido da membrana externa do que da camada adjacente de peptidoglicano, com conseqüente aumento do espaço periplásmico, e que os diferentes tamanhos vesiculares podem estar associados com a presença de compostos que determinam a união das membranas externa e interna.

As diferenças de eletrodensidade nas micrografias apresentadas, quanto aos tamanhos vesicula- res, permitem supor que estas sejam resultantes de diferentes interações do material amorfo com a membrana externa, inclusive com características citotóxicas $^{12}$. Também, foi observada a presença de A. actinomycetemcomitans no interior de uma $\mathrm{CEB}$, como já relatado anteriormente por diversos autores $^{5,14}$. Embora as células epiteliais tenham sido obtidas de um único doador, periodontalmente saudável e com higiene oral adequada, não se descarta a possibilidade de que esta invasão tenha ocorrido ainda na cavidade oral, previamente à coleta.

\section{CONCLUSÕES}

Fundamentados nas considerações anteriores, quando nossos resultados foram analisados permitiu-nos concluir que:

1. os isolados de A. actinomycetemcomitans testados mostraram capacidade variável de se aderirem às CEB;

2. a variabilidade na capacidade de aderência foi influenciada pelos repiques sucessivos;

3. os isolados A. actinomycetemcomitans que formaram grumos no isolamento inicial, não se prestaram adequadamente aos testes de aderência, pelo método ora empregado;

4. isolados que apresentaram elevados índices de aderência mostraram abundante quantidade de componentes extracelulares, os quais estariam diretamente relacionados ao mecanismo de aderência.

GASPARETTO, A.; ARANA-CHAVEZ, V. E.; AVILA-CAMPOS, M. J. Actinobacillus actinomycetemcomitans attached to oral epithelial cells: stabiblity and ultrastructural aspects. Pesqui Odontol Bras, v. 14, n. 4, p. 311-318, out./dez. 2000.

Actinobacillus actinomycetemcomitans is considered an important pathogen in periodontal disease, especially in localized juvenile periodontitis. The bacterial mechanism of adherence to oral epithelial cells (OEC), teeth or other bacteria is the initial step in colonization and in the pathogenesis of oral infectious processes, such as gingivitis and periodontitis. The goal of this study was to evaluate the adherence and its variability, as well as ultrastructural aspects of $A$. actinomycetemcomitans isolates on OEC, when they were submitted to repeated subcultures. Twenty-one fresh isolates from 21 patients with periodontal disease and one reference strain were tested. All tested isolates adhered to OEC and repeated subcultures produced variations in the adhesion rates of each isolate. Furthermore, a direct correlation between high levels of adherence and the presence of large amounts of extracellular components, such as fimbriae, vesicles and extracellular amorfous material, was observed.

UNITERMS: Bacterial adhesion; Actinobacillus actinomycetemcomitans; Periodontal diseases. 
GASPARETTO, A.; ARANA-CHAVEZ, V. E.; AVILA-CAMPOS, M. J. Aderência de Actinobacillus actinomycetemcomitans às células epiteliais bucais: estabilidade e aspectos ultra-estruturais. Pesqui Odontol Bras, v. 14, n. 4, p. 311-318, out./dez. 2000.

\section{REFERÊNCIAS BIBLIOGRÁFICAS}

1. AVILA-CAMPOS, M. J.; FARIAS, L. M.; CARVALHO, M. A. R. et al. Aspectos ecológicos de Actinobacillus actinomycetemcomitans: aislamiento y caracterización de cepas. Rev Lat-amer Microbiol. v. 30, n. 4, p. 301-305, Aug. 1988.

2. BLIX, I. J. S.; PREUS, H. R.; OLSEN, I. Invasive growth of Actinobacillus actinomycetemcomitans on solid medium (TSBV). Acta Odontol Scand, v. 48, n. 2, p. 313-318, Jun. 1990.

3. CAMPBELL, L. K.; KNOX, K. W.; WICKEN, A. J. Influence of growth conditions on adherence of Streptococcus mutans ingbritt to saliva-coated hydroxyapatite. Infect Immun, v. 39, n. 3, p. 445-448, Mar. 1983.

4. CHILDS III, W. C.; GIBBONS, R. J. Use of percoll density gradients for studing the attachment of bacteria to oral epithelial cells. J Dent Res, v. 67, n. 5, p. 826-830, Jun. 1988.

5. FIVES-TAYLOR, P.; MEYER, D.; MINTZ, K. Characteristics of Actinobacillus actinomycetemcomitans invasion of and adhesion to cultured epithelial cells. Adv Dent Res, v. 9, n. 4, p. 55-62, Mar. 1995.

6. Virulence factors of the periodontopathogen Actinobacillus actinomycetemcomitans. J Periodontol, v. 67, n. 4, p. 291-297, May 1996.

7. GIBBONS, R. J. Bacterial adhesion to oral tissues: a model for infectious diseases. J Dent Res, v. 68, n. 3, p. 750-760, June 1989.

8. KAGERMEIER, A. S.; LONDON, J. Actinobacillus actinomycetemcomitans strains Y4 and N27 adhere to hydroxyapatite by distinctive mechanisms. Infect Immun, v. 47, n. 4, p. 654-658, May 1985.

9. LOESCHE, W. J. Plaque-control in the handicapped: the treatment of specific plaque infections. J Can Assoc, v. 10, n. 2, p. 649-656, Apr. 1981.
10. MAYRAND, D.; GRENIER, D. Biological activities of outer membrane vesicles. Can J Microbiol, v. 35, n. 3, p. 607-613, July 1989.

11. MEYER, D. H.; SREENIVASAN, P. K.; FIVES-TAYLOR, P. M. Evidence for invasion of a human oral cell line by Actinobacillus actinomycetemcomitans. Infect Immun, v. 59, n. 4, p. 2719-2726, Aug. 1991.

12. MEYER, D. H.; FIVES-TAYLOR, P. M. Evidence that extracellular components function in adherence of Actinobacillus actinomycetemcomitans to epithelial cells. Infect Immun, v. 61, n. 4, p. 4933-4936, June 1993.

13. MEYER, D. H.; FIVES-TAYLOR, P. M. Characteristics of adherence of Actinobacillus actinomycetemcomitans to epithelial cells. Infect Immun, v. 62, n. 2, p. 928-935, Mar. 1994.

14. MEYER, D. H.; LIPPMANN, J. E.; FIVES-TAYLOR, P. M. Invasion of epithelial cells by Actinobacillus actinomycetemcomitans: a dinamic, multistep process. Infect Immun, v. 64, n. 3, p. 2988-2997, July 1996.

15. PAGE, R. C. Critical issues in periodontal research. J Dent Res, v. 74, n. 4, p. 1118-1128, Mar. 1995.

16. SLOTS, J. Selective medium for isolation of Actinobacillus actinomycetemcomitans. J Clin Microbiol, v. 15, n. 5, p. 606-609, Mar. 1982.

17. Salient biochemical characters of Actinobacillus actinomycetemcomitans. Arch Microbiol, v. 13, n. 5, p. 60-67, June 1982.

18. Actinobacillus actinomycetemcomitans. In: NISENGARD, R. J.; NEWMAN, M. G. ed. Oral Microbiology and Immunology. Philadelphia : W. B. Saunders Co., 1994. p. 218.

19. WENSINK, J.; WITHOLT, B. Outer-membrane vesicles released by normally growing Escherichia coli contain very little lipoprotein. Eur J Biochem, v. 116, n. 4, p. 331-335, June 1981.
Recebido para publicação em 08/01/00 Enviado para reformulação em 03/06/00 Aceito para publicação em 18/08/00 